\title{
The Development of Low Carbon Manufacturing Industry in
}

\section{Hainan Province}

\author{
Xi Wang \\ Business Administration Department, Hainan College of Economics and Business, Haikou, Hainan Province, China \\ Corresponding author: cissywx2016@163.com
}

\begin{abstract}
As the main part of industrial production, the manufacturing industry promotes the economic growth of our country, but the subsequent large amount of energy consumption and greenhouse gas emissions have greatly undermined human's living environment. Therefore this paper aims at finding some solutions through the example of Hainan's low carbon manufacturing industry. It first analyzes the importance of low carbon economy for the development of the manufacturing industry, then describes the current status of Hainan's low carbon manufacturing industry, and finally puts forward five ways for the development of low carbon manufacturing in Hainan Province such as perfecting relevant laws and regulations, formulating supporting policies, setting up suitable industrial layout, improving the low-carbon technology innovation system, and establishing incentive mechanism of personnel in manufacturing enterprises. The third part is also the main innovation in this field.
\end{abstract}

\section{The importance of low carbon economy to the development of manufacturing industry}

Low carbon manufacturing industry is major breakthrough with low resource consumption and less environmental pollution [1]. The application of low carbon technology can increase productivity, reduce carbon emissions, realize the real clean production as well as improve the competitiveness of manufacturing industry.

\subsection{Low carbon economy can enhance the scale and competitiveness of manufacturing}

From the perspective of enterprise scale, manufacturing enterprises in China are scattered with small scale and low industrial concentration. Besides, the popularizing rate of energy-saving technology and related equipment is low. And, few ones have possessed their own brand and enter the world-top 500 large enterprises [2]. Low carbon technology can improve the comprehensive utilization of resources, optimize the allocation of resources as well as reduce enterprise cost, which contributes a lot to creating lower carbonation products, meeting consumer demand for low carbon products, adapting to the market demand in an effectively way. It is also beneficial for enhancing product competitiveness, and expanding the scale of industry. In addition, the application of low-carbon technology can phase out the large enterprises with relatively low-technical level, high-energy consumption as well as much pollution on environment. As a result, the enterprise with the core technology and innovation ability can acquire small businesses by means of relying on technology and innovation advantages, and thus quickly realize scale expansion, strengthen the intensive industry, and improve the efficiency of the industrial economy of scale. 


\subsection{Low carbon economy can promote the sustainable development of manufacturing industry}

Low carbon economy means traditional ecological technology enterprises will gradually be replaced by more environmentally friendly low carbon technology, which can help enterprises realize green and ecological manufacturing, such as green design, green process planning, the selection of green materials and so on [3]. If manufacturing enterprises can make full use of low carbon technology for production, they will consume fewer resources, prevent environmental pollution, realize sustainable development, and comprehensively enhance their competitive advantages.

\subsection{Low carbon economy can help develop new industries}

Low carbon manufacturing is an important part of the development of emerging industries in china. The government has begun to advocate the application of low carbon technology in manufacturing enterprises, which accelerates the upgrading of manufacturing industry in our country, promotes the implementation of energy saving and emission reduction project, produces a great number of energy-efficient equipment and lead to the development of new industries [4]. What's more, the development of new industries will promote the steady growth of China's economy and help to realize sustainable development.

\section{The development of low carbon manufacturing in Hainan}

Since Hainan was listed in the second batch of low carbon pilot provinces by the state in 2012, Hainan has spared no effort to pursuing the development of low carbon manufacturing, and also achieving a lot of results.

\subsection{Low carbon manufacturing output has grown steadily}

During the "twelfth five-year" period, the low-carbon manufacturing industry of Hainan grew at the rate of $6.7 \%$ on every year, consumed only $2.2 \%$ of the industrial energy and contributed more than $25 \%$ of the industrial added value. Besides, it became the important support for the industrial optimization structure, transformation and upgrading of Hainan. Although the total profit of the low carbon manufacturing in Hainan province declined slightly from 2012 to 2015, their gross industrial output value, industrial added value, prime operating revenue increased to different extent, showing the low carbon manufacturing of Hainan province presented steady growth.

\subsection{Low carbon manufacturing enterprises ascend innovation ability}

By the end of 2015, there were 1800 low carbon manufacturing enterprises in Hainan province, including 200 scale enterprises, and they formed a larger scale of industry cluster in the fields of automobile manufacturing, biomedicine, new energy, new material and tropical agricultural products processing. Meanwhile, enterprises have improved innovation ability constantly, and more than half of the 169 high-tech enterprises in Hainan province belong to low carbon manufacturing enterprises. For example, Sanya ZTE Co., Ltd was the world's first enterprise to introduce the formal commercial H. 265 standard video terminal in 2015, and realized the software MCU and end products series software supporting cloud deployment; Hainan Litree Water Purification Technology Industry Co., Ltd contributed its technology to becoming shareholder of Russia Ecolos Group, building membrane technology water purification facilities with the total investment of over $\$ 100$ million, as well as becoming the first high-tech enterprise in Hainan to be the shareholder of foreign factories by intellectual property rights.

\subsection{The gradual appearance of green development}

Low carbon manufacturing has made significant breakthrough in the field of saving energy and reducing consumption. In 2015, low carbon manufacturing of Hainan province consumed $1.9 \%$ of the total industrial energy, and contributed to more than $25 \%$ of the industry GDP. Besides, it made great contributions to the industrial saving energy and reducing 
consumption. Meanwhile, the oil and gas chemical industry, mineral processing and other traditional energy-intensive industries effectively controlled energy consumption, and the new comprehensive energy consumption of new products of some industry has reached the leading domestic level. In 2015, the industrial ten thousand Yuan GDP energy consumption in Hainan province fell to 2.331 tons of standard coal; pollutants such as chemical oxygen demand (COD) and sulfur dioxide (SO2) were brought under the control [5]; industrial structure is gradually optimized, and green, low carbon development trend have become increasingly obvious.

\section{Development strategy of low carbon manufacturing industry in Hainan province}

Hainan province should form a low carbon manufacturing industry with Hainan characteristics under the strategy of the Belt and Road, Made in China 2025, the development of the South China Sea. The followings are some suggestions.

\subsection{Formulate relevant laws and regulations}

At present, our country has not set up special laws and regulations for the development of low carbon manufacturing industry. Therefore, Hainan province should learn from other provinces and countries, formulate relevant laws and regulations to support the development of low carbon manufacturing industry, set out a standard system covering energy-saving production equipment, monitoring and management, energy management and auditing etc. [6]. For example, "Energy Conservation Regulations in Hainan Province" has made specific provisions on the construction of energy-saving industrial structure, which strengthens energy conservation supervision and improves energy-saving mechanism etc.. More similar regulations should be promulgated in the near future so as to provide a strong legal protection for the development of low carbon manufacturing industry in Hainan.

\subsection{Formulate related policy and form the long-term mechanism of low carbon industry development}

Formulate related policy and form the long-term mechanism of low carbon industry development. Due to the large risks and slow returns of low carbon industry, many enterprises are reluctant to invest. Thus, the government subsidies are required. Government departments should formulate the corresponding subsidy policy to encourage enterprises to conduct low carbon industry research and investment. For example, Special Fund Management Interim Measures for Low Carbon Industry Development of Hainan Province (hereinafter referred to as the Measures) stipulates that the provincial government should allocate special funds to support development of low carbon manufacturing every year, and give special funds in principle, in the way of loans with discounted interest, special subsidies, incentives, and equity investment. In addition, special funds are used for supporting the product $R \& D$, technical innovation, brand building and talent incentive of the low carbon manufacturing industry enterprises in the fields of high-end equipment manufacturing (including new energy automobile, electrical and mechanical equipment, marine engineering equipment manufacturing and cruise yacht), green food processing, new energy, new materials and intelligent manufacture. In addition, the related policies, such as tax policy, price policy, and science and technology policy should be formulated as soon as possible, so as to optimize the financing environment of low carbon manufacturing, broaden the financing channels, and encourage all kinds of capital, and provide financing support for enterprise development from the aspects of innovation ability construction, technical transformation and industrialization, as well as enterprise merger and reorganization, which can eventually form long-term investment mechanism and provide policy support platform.

\subsection{Set up suitable industrial layout}

Hainan should focus on creating advantageous manufacturing industry of its own characteristics to maximize the benefits of limited resources. According to the "Made in China, 2025", Hainan will vigorously promote the development of pharmaceutical industry, automobile manufacturing, electronics manufacturing, marine equipment manufacturing, tourism manufacturing, new energy and materials, agricultural and sideline products processing, tropical 
marine biological industry, the integration of military and civilian industry and the oil and gas industry in the next ten years. And Hainan will also strive to set up a number of leading domestic manufacturing enterprises, brands and products as well as several industrial parks with complete functions and advanced facilities [7]. After determining the key areas, the government should actively improve the development of organizational leadership, policy environment, financing channels, investment-invitation and personnel structure to get out of a long-term development of the road.

\subsection{Improve the low carbon technology innovation system}

On the one hand, capital investment for low carbon technology innovation should be emphasized. Low carbon manufacturing enterprises should increase investment in new energy technology innovation to provide financial support for the application of new technologies [8]. On the other hand, low carbon technology innovation should be strengthened. The manufacturing industry can improve the technology innovation level by employing the advanced technical talents, cooperating with other enterprises and institutions, and introducing foreign advanced technology and so on. For instance, a number of enterprises reached a cooperation agreement, signed 15 cooperation projects such as new energy vehicles, marine equipment, civil military integration, 3D printing, sensors, seafood processing, etc. on a low-carbon manufacturing investment forum on July 29, 2016, in Hainan. These projects help promote technology innovation level of new energy vehicles and tropical agricultural products processing in Hainan Province, and lay a solid foundation for the development of the integration of military and civilian industry in Hainan.

\subsection{Establish the incentive mechanism of personnel}

As one of the new economic growth points in Hainan Province, Low carbon manufacturing industry needs a large number of excellent personnel who can help accelerate industrial development [9]. Therefore, the government should formulate relevant policies as soon as possible to attract high-level talents, while manufacturing enterprises should introduce and cultivate engineers and technicians in this field. Besides the talent introduction mechanism, in order to lay a solid foundation for the development and give full play to the initiative of high-level personnel, enterprises should also establish the incentive mechanism and make use of various supporting measures to motivate employees to improve their professional skills. For example, the manufacturer can gradually establish a full range of multi-channel human capital security system, which guarantees senior employees their housing, family employment, social insurance and other benefits. Finally, the enterprise should form a cultural atmosphere for innovation, encourage all staff try their best to learn new low carbon technology, which can lead to the development of low carbon manufacturing industry.

\section{Conclusion}

During the past five years, Hainan's low carbon manufacturing industry has witnessed its great development. However, there is still a long way to go to realize the optimization of the development. So the government departments and relevant enterprises shall work together to explore new ways and modes for further development from such aspects as regulations and policies, industrial layout, technological innovation and incentive system. In the next few years, Hainan's manufacturing industry will truly realize the rise of green low carbon.

\section{References}

1. Z.J. Liang, Create the Six Major Industries Around “Three Main Lines” Hainan daily (2015).

2. X.Y. Duan, Y.H. Zhang, The Low Carbon Road of Manufacturing Industry in China Environmental Protection 35 (2010).

3. R.S. Li, Research on the Core Competence of China's Manufacturing Eenterprises in Low Carbon Economy Ph D Thesis. Harbin University, 30 (2011). 
4. H.J. Cao, H.C. Li, Y.B. Du, X.G. Li, The Research Status, Development Trends and Challenges of Low Carbon Manufacturing Aviation Manufacturing Technology, 28 (2012).

5. Z.J. Liang, The New Industry Road of Hainan Hainan daily (2013).

6. Chongqing Municipal People's Government Office on the Issuance of Chongqing City to Strengthen Energy Conservation Standardization Implementation Plan (2015).

7. Hainan's Manufacturing Industry Focus on 9 Areas, www.hainan.gov.cn.

8. J.B. Zhao, A Study on the Impact of Low Carbon Technology Innovation of Manufacturing Iindustry Master Thesis. Harbin University, 36 (2013).

9. Analysis Of the Introduction of Overseas High-level Personnel System in Hainan Province, http://hi.lss.gov.cn (2015). 